\title{
The edible cocktail: the effect of sugar and alcohol impregnation on the crunchiness of fruit
}

\author{
Elke Scholten ${ }^{1 *}$ and Miriam Peters ${ }^{1,2}$
}

\begin{abstract}
Background: Vacuum impregnation is seen as a valuable technique for flavor pairing in the catering industry. One of the applications of this technique is the creation of edible cocktails by impregnating fruits with liquors, leading to an interplay of different flavors. However, the effect of the impregnation of sugar and alcohol into the fruit will affect the texture of the fruit and therefore its crunchiness. Thus, the positive effect of flavor pairing might be inhibited by a negative effect in texture changes.

Results: This investigation focused on the change in crunchiness as a result of the impregnation of different sugar and alcohol containing solutions. When hypotonic solutions were used, the impregnation resulted in the rupture of the cells, thereby leading to a decrease in crunchiness. When hypertonic solutions were used, the cells shrunk, which also resulted in a decrease in crunchiness. Isotonic solutions resulted in crunchiness comparable to its fresh version. When alcohol was used, the crunchiness decreased at all concentrations investigated.

Conclusions: Crunchiness of fruit can only be maintained when impregnated with isotonic sugar solutions. When the sugar or alcohol content deviates from that in the fruit, impregnation of these liquids will lead to a decrease in crunchiness. This has consequences for the creation of edible cocktails: for an optimal crunchiness, the sugar content of the impregnation liquid has to be equal to the sugar content of the fruit or vegetable.
\end{abstract}

\section{Background}

The impregnation of different solutes into porous materials is an important process in the food industry. As the demand for healthy and natural products is increasing, processes are being used to adjust food system formulations by processes like osmotic dehydration, impregnation and ultrasound treatments [1-7]. Examples can be found where fruits and vegetables are enriched with cryoprotectants, calcium or zinc [8-10]. The amount of solutes and liquid that can be absorbed by the porous products depends on two diffusion processes: molecular and capillary diffusion $[2,11,12]$, which are influenced by parameters such as surface tension, pore size, porosity, and others. The process is often slow and absorption of liquids is limited. To overcome these limitations, vacuum impregnation is more often used [2-4,10]. This technique applies a reduced pressure to porous materials, which expands the air in the open spaces and forces it to leave the porous

\footnotetext{
* Correspondence: elke.scholten@wur.nl

${ }^{1}$ Food Physics Group, Department of Agrotechnology and Food Sciences,

Wageningen University, Bomenweg 26703HDWageningen, the Netherlands

Full list of author information is available at the end of the article
}

material [13]. As the air flows out of the pores, any surrounding liquid is allowed to flow in through the capillary pores, a phenomenon called hydrodynamic mechanism (HDM). The pressure change can promote deformations in the product due to the viscoelastic properties of the matrix, which leads to the coupling of the HDM with deformation-relaxation phenomena (DRP) [14]. Due to the simultaneous expansion of air and flow of liquid, air in porous products can be substituted with surrounding liquids. This technique therefore allows the uptake of more liquid in a shorter period of time [13]. It offers the possibility to impregnate any porous matter with any liquid, which makes pairing of a large variety of food materials with different liquids possible.

Vacuum impregnation is a very simple technique to fill porous materials with liquids and therefore offers opportunities in restaurants, bars and the retail sector. Recently, restaurants and bars have been exploring the options of using these industrial techniques to create different textures and combinations of flavors in their dishes $[15,16]$. Almost all food products that are used in these sectors are porous materials, such as meat, fish, fruit and vegetables,

\section{Biomed Central}


and can be impregnated or marinated with oils and flavored liquids. Combinations of chocolate milk in strawberries, orange juice in apple and vodka in cucumber are just a few examples of the many combinations possible. Liquor-filled pieces of fruit are described as edible cocktails, and combine the flavor of the liquor with the texture of fruit. Besides affecting the flavor of the fruit, the impregnations of these sweet and alcoholic liquids also have an effect on the texture of the fruits and vegetables. The type of incorporated liquid can lead to dramatic structural changes of the fruit, which lead to changes in sensory perception. Although the change in flavor might have beneficial effects, the dramatic changes in the texture of the fruit might lead to detrimental effects in these edible cocktails. This work focuses on the structural changes of the edible cocktails when impregnated with sugar and alcohol solutions. The change in texture is examined by investigation of the crunchiness (toughness) of the fruit.

\section{Results and discussion}

\section{Weight gain of impregnated fruit}

The impregnation of different solutes into fruits and vegetables has an effect on texture. During the impregnation, air pockets or interstitial spaces between cells are filled by the impregnation liquid. This will give rise to a difference in osmotic pressure within the porous material [13]. As a result, osmosis will occur that will lead to the flow of liquids and solutes. The osmotic treatment can have different effects on the food material, depending on the nature of the osmotic solutions. Three types of solutions can be distinguished: isotonic, a solution containing a similar concentration of solutes as the food material; hypotonic, a solution containing less solute molecules than the food material; and hypertonic, a solution containing more solute molecules than the food material [13]. Osmosis will lead to a change in pressure of the cells (turgor pressure) and will have an effect on the cell size and the weight gain of the fruit samples. Figure 1 shows the weight gain for an apple, melon and cucumber impregnated in sugar solutions with different concentrations.

When isotonic solutions are used, no net liquid flow will occur and the plant cell sizes will not change. Total weight gain of the samples at these concentrations can be regarded as the weight gain due to the filling of the interstitial spaces only, and can be used to calculate the porosity of the fruit. Isotonic solutions are sugar solutions with an equal concentration of sugar as the fruit itself. In fruits, the sugar concentration is given as a brix value $\left({ }^{\circ} \mathrm{Bx}\right)$, which contains the contributions of the different sugars present in fruits and vegetables (for example, sucrose and fructose). Refractive index measurement results in $12^{\circ} \mathrm{Bx}$ for apples (equivalent to $12 \% \mathrm{wt} / \mathrm{wt}$ sucrose), $6^{\circ} \mathrm{Bx}$ for melon (equivalent to $6 \%$ wt/wt sucrose) and negligible values for cucumber. This

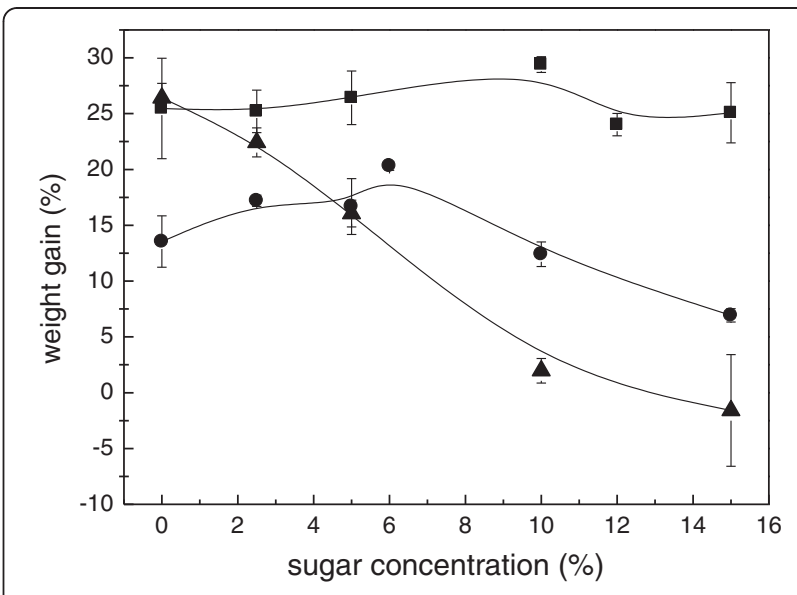

Figure 1 The increase in weight (percentage) as a function of the concentration of sugar solution. Squares represent the result for apple, circles represent the results for melon and triangles represent the results for cucumber. The line was added to guide the eye.

is in agreement with values found previously [17]. This brix value is used in the calculation of porosity, which works out as $30 \%$ for apple, comparable to results found previously [4], 20\% for melon and 25\% for cucumber.

At sucrose concentrations different from the brix values of the fruit itself, osmotic differences will lead to changes in the cell structure as a flow of liquid and solutes is generated. In hypotonic solutions (low sugar concentration), the osmotic pressure within the cells is higher than in its surroundings. To decrease the difference in pressure, water will flow into the cells and solutes diffuse to the outside. This will lead to the swelling of the cells, and may lead to rupture, thereby destroying the cell wall. For the melon, we see that the weight gain at low sugar concentrations is decreased in comparison to in an isotonic solution. As melon has a soft structure, it is reasonable to assume that the cell swelling leads to rupture of the cells. As the liquid is now allowed to flow from the cells, the total weight gain decreases as the amount of intact cells is reduced. This effect is less visible in the case of apple, which has a firmer structure. As the cucumber does not contain any sugar, no hypotonic osmosis is observed.

On the other hand, when placed in hypertonic solutions, cells will shrink as water will be pulled out of the cells to decrease the pressure in the surrounding solutions. At the same time, the sugar diffuses into the plant cells. However, as the sugar molecules are much larger than water molecules, diffusion will be limited as the molecules have to diffuse through the network of the cell wall. The composition of the cell wall determines the total amount of solute that can penetrate through the cell. For both melon and cucumber, we see a large decrease in weight gain in hypertonic impregnation solutions compared to in isotonic solutions. This is a result 
of the shrinkage of the cells that leads to a collapse of the structure. Although we see large differences for melon and cucumber, the weight gain for apple does not show dramatic changes. However, as apple contains a large amount of sugar, this effect will only occur at sugar concentrations higher than $12 \% \mathrm{wt} / \mathrm{wt}$, and the effect is therefore very limited in this concentration range. As the results for the melon and cucumber show, hypertonic solutions lead to water removal from the cells and are therefore often used to dehydrate fruit samples [3,6,18].

These results show that the weight gain for the melon and the cucumber is largest when the samples are placed in an isotonic solution; no change in plant cell size has occurred. When the samples are placed in either a hyperor hypotonic solution, we see a decrease in the weight gain, and therefore a dramatic change in the structure of the fruit. However, impregnation of the apple does not result in large differences in weight gain regardless of the type of solution. Apparently, the structure is not that much affected by the solutions compared to the much softer melon and cucumber. Overall, the degree of shrinkage for concentrated sugar solutions (15\% wt/wt) is related to the sugar content of the fruit; apple, containing the highest concentration of sugar, shows the least effect; cucumber, containing the lowest concentration, shows the largest effect.

Figure 2 shows the weight gain of apple, melon and cucumber impregnated in ethanol solutions. In the case of impregnation with alcohol solutions, both water and alcohol will flow into the samples and sugar diffuses out. The rate of diffusion will depend on the size of the different molecules. As water is the smallest molecule, it will have the largest diffusion capacity. Sugar is the largest and will therefore have the lowest diffusion capacity through the

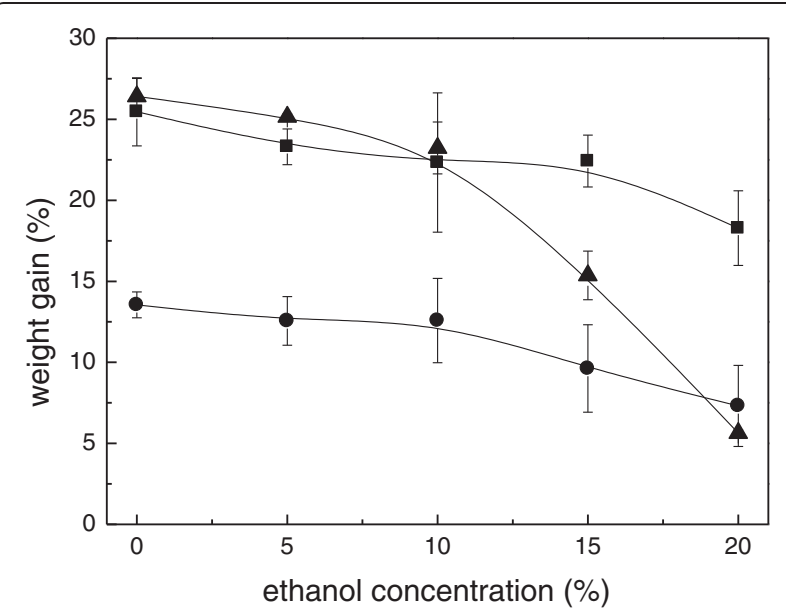

Figure 2 The increase in weight (percentage) as a function of the concentration of ethanol. Squares represent the result for apple, th circles represent the results for melon and triangles represent the results for cucumber. The line was added to guide the eye. cell wall. The ratio between the different diffusion coefficients and the immersion time will determine the relative changes of the solution and solutes. The interplay between the three diffusion processes will determine the total flow, and depends on the osmolarities of the solutes and the permeability of the cell walls. As can be seen, the weight of the sugar-containing apple and melon does not change dramatically. The diffusion rates for water, ethanol and sugar are in balance to some extent. When placed in high concentrations of alcohol, a slightly larger decrease in overall weight gain is observed: water is being pulled out of the cells. Apparently, the water flux from inside to outside of the cells is larger than the ethanol flux into the cells. Even though the apple and the melon do not show large differences in weight gain, the cucumber does. Similar to the impregnation with sugar solutions, the weight gain for the cucumber samples decreases with an increase in ethanol concentration. However, the total decrease in weight gain for higher ethanol concentrations is less than in the case of concentrated sugar solutions. As the osmolarity of an ethanol solution is approximately three times larger than the osmolarity of a sugar solution, the driving force for water extraction would be much higher using ethanol solutions, and should therefore result in larger cell shrinkage. As this is not the case, we can conclude that osmolarity by itself is not the only driving force for liquid flow. Apparently, the diffusion of ethanol determines to a great extent the exchange of liquids and solutes in the cells. As can be seen, the diffusion of ethanol into the cells is much faster than the diffusion of sugar. The diffusion coefficient (and thus the size of the solute) determines the total water flow. The larger the solute, the slower the diffusion through the cells, the more water is pushed out before equilibrium is reached, which leads to a larger weight loss (compared to isotonic conditions).

\section{Fracture toughness measurements}

The mechanical properties of the fruit are mainly responsible for the fracture behavior of these materials and will define their sensory attributes. Vincent and coworkers showed that the stress needed to crack a certain fruit sample is closely related to the sensory attributes of hardness and crunchiness [19,20]. The general fracture behavior of fruit can be ascribed to two different failure modes within the sample: cell separation and cell rupture $[8,21]$. The type of failure mode depends largely on the turgor pressure of the cells; cell debonding is more likely to occur at low turgor pressure and cell rupture at higher turgor pressure. The fracture (mechanical) properties of the impregnated fruit samples were measured with a three point bending test. The samples were placed on the support and loaded with a cell. Force displacements curves were recorded for all samples, for which the maximum load, $P_{c}$, before fracture was noted. Examples for 
force displacement curves for untreated and waterimpregnated fruit samples are shown in Figure 3.

These force displacement curves are approximately linear up to a certain critical load, at which one of the cracks propagates. As the crack gets arrested, the load is increased again, and decreased the moment another crack appears. The fracture toughness of the samples was calculated according to Equation 2. The maximal load used, needed to calculate the fracture toughness, is very dependent on differences in the samples, and therefore the test was done three times to obtain an averaged value. The solid lines in Figure 3 show the fracture behavior for the untreated samples. As can be seen, the fracture toughness of a fresh apple is highest, but impregnation with water leads to a large decrease in the maximal load. The maximal load for impregnating cucumber, on the other hand, does not differ significantly between untreated and impregnated samples.

Overall, the impregnation of the fruits had a negative effect on the fracture toughness compared to fresh fruit. The cucumber impregnated with $15 \% \mathrm{wt} / \mathrm{wt}$ of sugar does not even fracture, becoming too soft. A similar result is obtained for the melon with $5 \% \mathrm{wt} / \mathrm{wt}$ of ethanol.

Figure 4 shows the result of the fracture toughness of the samples impregnated with sugar solutions. As can be seen, the error bars of the measurements are quite large, which reflects the difficulty of working with real fruit systems. Fruit tissues are often anisotropic and therefore large fluctuations in fracture can be observed [22]. Fracture will occur along the weakest pathway of resistance, and will therefore largely depend on the tissue structure and the orientation of the network. Even though the samples were all loaded in the same direction, differences in fracture behavior are still visible.

The fracture toughness reflects the fracture behavior of the fruits through cell rupture and cell separation, which is mainly influenced by the cell turgor pressure and the composition of the cell wall and the lamellae. Despite these large fluctuations in the fracture toughness, a clear trend can be observed for the three fruit types. The largest fracture toughness is found in isotonic solutions; around 12\% $\mathrm{wt} / \mathrm{wt}$ for the apple, $6 \% \mathrm{wt} / \mathrm{wt}$ for the melon and $0 \%$ for the cucumber. These values are the most comparable with the values for the untreated fresh sample. At these concentrations of sugar, the cell turgor pressure does not change, and no large changes in fracture toughness due to cell rupture will be present. However, when hypo- and hypertonic solutions are used, the turgor pressure on the cell wall does change. In hypotonic solutions, the cells swell, and according to the weight gain experiments, cell rupture has a)

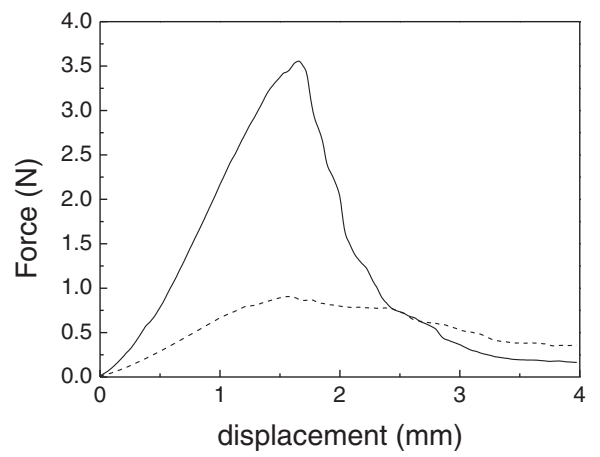

c)

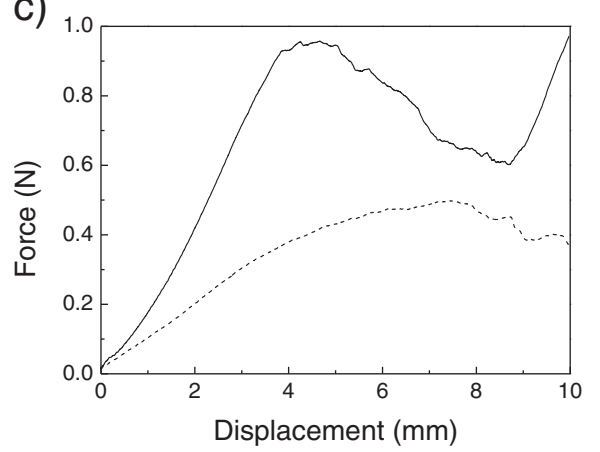

b)

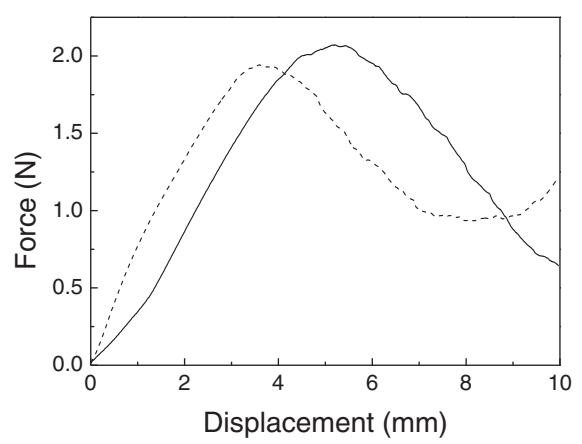


a)

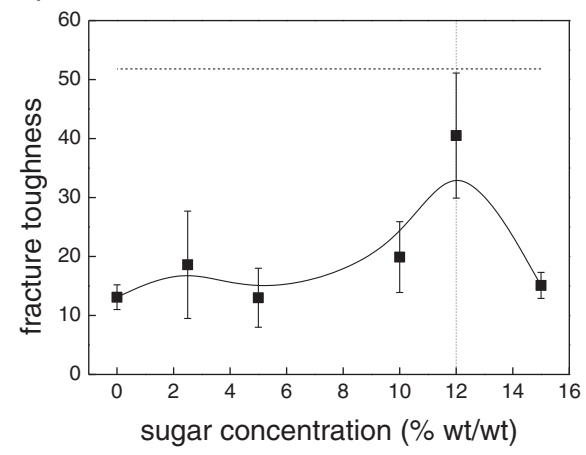

c)

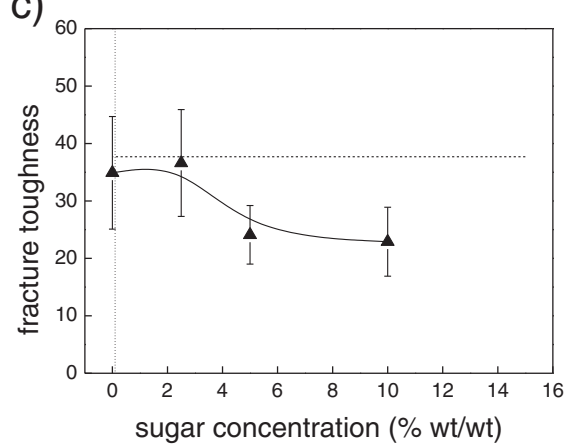

b)

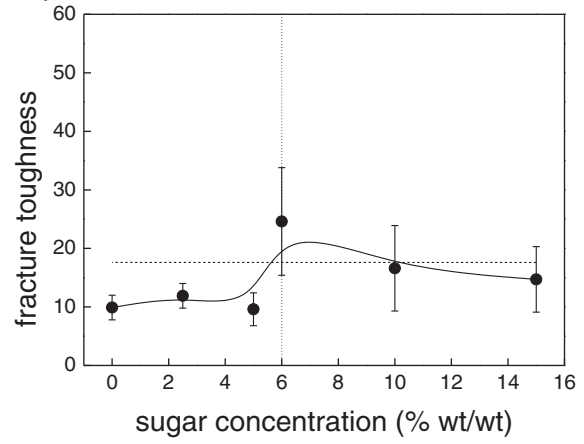

Figure 4 The fracture toughness as a function of the concentration of sugar. (a) Squares represent the result for apple; (b) circles represent the results for melon; (c) triangles represent the results for cucumber. The line was added to guide the eye. Dashed horizontal line refers to the toughness of an untreated sample. Dotted vertical line refers to the isotonic solution.

probably occurred. As the cell ruptures, fracture toughness decreases, which is clearly visible in Figure 5. Had cell rupture not occurred, cell fracture would have been more difficult, which would have led to higher fracture toughness. In the case of hypertonic solutions, water is extracted from the cells, which causes a loss in turgor pressure (shrinkage of the cells) and a decrease in cell wall elasticity. This leads to a decrease in the fracture toughness.

Although the pressure seems to be the most important parameter responsible for the mechanical properties of fruit samples, other attributes have also been shown to contribute: cell wall resistance, cell bonding, cell density and porosity [8]. Cell separation, especially, is an important factor [21]. The impregnation solutions have an effect on the cell walls and the lamellae between the cells. The solutes in the solutions have the ability to change the composition of the cell wall. Plant cell walls consist of polysaccharides, such as pectins, celluloses, hemicelluloses, starch and galactomannans, which can be found in the primary cell wall and the middle lamellae [23]. These polysaccharides can be degraded (by age or solutes) and determine the composition and, therefore, the strength of the cell wall. Pectin, one of the polysaccharide, has been found to have the largest effect on fruit softening, as the dissolution of pectin leads to weaker cell walls and the dissolution of the middle lamellae, leading to separation of the plant cells [7,10,18,23-26]. The incorporation of liquid sugar solutions leads to solubilization of the pectin and decreases the cell adhesion. This leads to a decrease in fracture toughness, which is visible for all fruits as the fracture toughness of all the impregnated samples was lower than the fracture toughness of fresh fruit.

Figure 5 shows the fracture toughness for the samples impregnated with the alcohol solutions. During the impregnation, water diffuses out of the cells while ethanol will diffuse into the cells, until equilibrium in osmotic pressure is reached. The exchange of water for ethanol has already been shown to cause shrinkage of cells in the case of apples [27].

There was a large decrease in fracture toughness for apple and melon in ethanol solutions compared to sugar solutions. For cucumber, we see a similar negative effect as in the case of the sugar impregnation. Even though the ethanol solution will have an osmotic pressure comparable to the fruit's cells at a certain concentration, it appears that the presence of alcohol has a larger effect than just the effect on turgor pressure. This is probably due to cell separation instead of cell rupture. When the ethanol is drawn into the cells, it changes the composition of the cell walls and the strength of the lamellae. The cell wall 
a)

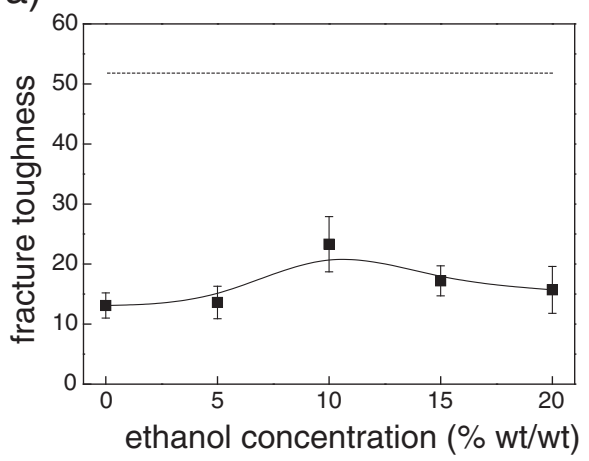

b)

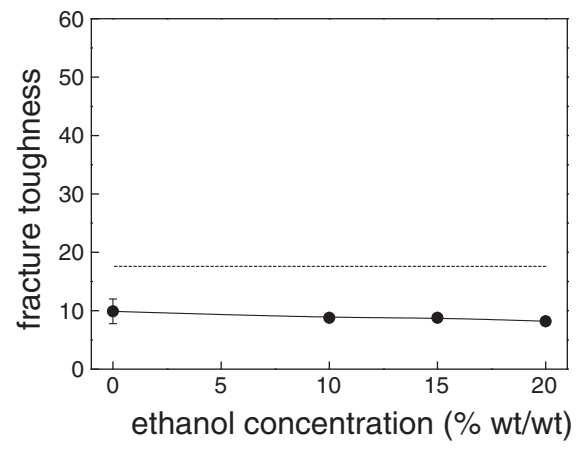

C)

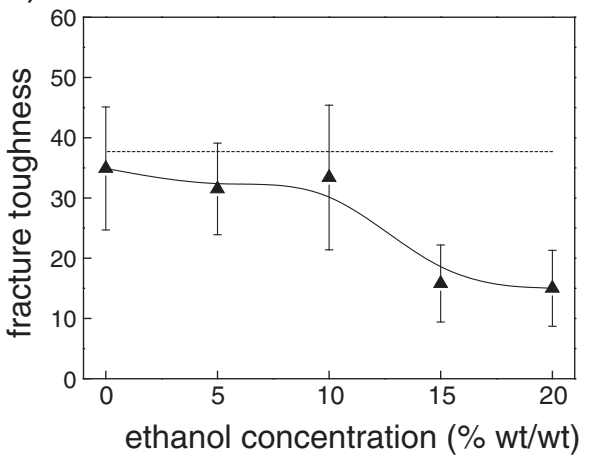

Figure 5 The fracture toughness as a function of the concentration of alcohol. (a) Squares represent the result for apple; (b) circles represent the results for melon; (c) triangles represent the results for cucumber. The line was added to guide the eye. Dashed horizontal line refers to the toughness of an untreated sample.

polysaccharides are soluble in water, but mostly insoluble in ethanol so they precipitate out. This precipitation distorts the network and its strength. For apple and melon, we see that the fracture toughness for ethanol-impregnated samples is much lower than for sugar-impregnated samples. The presence of ethanol therefore seems to have a negative effect on the cell wall strength. Apparently, the precipitation of the polysaccharides leads to a loss in cell wall strength and, therefore, increased ease of cell separation or debonding. However, the exact contributions of cell rupture and cell separation are not clear. Although research can be found on the cell tissue structure for osmotic hydrated fruit, the effect of alcohol on the cell structure has not been studied extensively.

The effect of impregnation of liquors into fruit: The edible cocktails, practical implications

Vacuum impregnation has proven to be an effective method to incorporate liquids into porous fruits and vegetables. This provides the opportunity to combine different flavors of fruit with additional flavored liquids. In the catering and beverage industry, it can be used to combine fruits, such as apples and cucumber, with alcoholic beverages, such as vodka and martini, to create impregnated fruit samples, also known as edible cocktails. These edible cocktails can be made by placing a small piece of fruit in a liquid-filled container (a combination of liquor, sugar solution and flavored water), and then placing the container in a vacuum sealer. The vacuum should be applied for roughly 30 minutes to allow the air to escape, after which the vacuum showed be released slowly to allow the liquid to enter the fruit gradually and fill all available pores. When this exercise is performed, the liquids and its flavors are infused into the fruit. However, not only the flavors of these products will change, but also the texture of the fruit and therefore the sensory perception. Using this method for flavor pairing, one therefore has to keep in mind that it comes with a change in texture, which might be detrimental to consumers' perception. If one would like to keep the crunchiness and hardness of the fruit, the fruit should be infused with isotonic solutions. The sugar concentration of the fruit can be determined using a Brix meter. One degree of Brix is equivalent to a $1 \%$ sugar solution. For example, a fruit with a Brix value of 10 will best maintain its crunchiness and hardness with liquid that contains $10 \%$ sugar (wt/wt). Large deviations from the sugar content of the fruit will likely lead to a loss of texture. The 
impregnation of alcohol always leads to a decrease in the texture and will make the fruit much softer.

\section{Conclusion}

Vacuum impregnation has been evaluated as a new technique for flavor pairing in restaurants and bars. The technique can be used to infuse different liquids into porous materials, such as meat, fish, fruit and vegetables. This research focused on the impregnation of different sugar- and ethanol-containing liquids into fruits. Although the combination of flavors can be a positive contribution to a dish, the change in texture could be detrimental to consumers' perception. This research therefore focused on the effect on texture of impregnation with different solutes into apple, melon and cucumber. The impregnation of sugar and alcohol solutions into the three different types of fruit resulted in a large change in weight gain and fracture toughness. When isotonic solutions were used, maximum weight gain and maximum fracture toughness were found. This indicated an unchanged cell structure; fracture behavior was maintained. When impregnated with hypotonic solutions, a lower weight gain and decreased fracture toughness was found. This could be attributed to cell swelling and rupture. Hypertonic solutions induced cell shrinkage and cell debonding, which also led to a lower weight gain and decreased fracture toughness. The impregnation of alcohol led to a decrease in fracture toughness in all cases. These results show that the impregnation of fruit samples with different liquids, either sugar- or alcoholcontaining, has a large influence on the crunchiness of the fruit.

\section{Methods}

\section{Materials}

The fruits used in this study were apple (Elstar), melon (Galia) and cucumber and were purchased from a local store. They were selected on the basis of size and visual absence of damages. They were stored at room temperature and used within one day of purchase. The solutions for impregnation were prepared with sucrose and ethanol. The sucrose was obtained from Suikerunie (Oud-Gastel, the Netherlands). Ethanol was obtained from Sigma-Aldrich (Zwijndrecht, the Netherlands). The solutions were prepared with demineralized water.

\section{Sample preparation for impregnation treatments}

The apple, melon and cucumber were cut in small pieces of roughly $4.0 \times 1.0 \times 0.8 \mathrm{~cm}$. Pieces were cut in identical directions within the fruit tissue to avoid differences in cell build-up. Skin and seed areas were avoided to create homogeneous textures and the pieces were weighed and measured before use. Three pieces of each kind were placed in a container that contained $50 \mathrm{~mL}$ of the impregnation solution. These solutions contained either sugar $(0 \%, 2.5 \%, 5 \%, 6 \%, 10 \%, 12 \%$ and $15 \% \mathrm{wt} / \mathrm{wt})$ or alcohol $(0 \%, 5 \%, 10 \%, 15 \%$ or $20 \% \mathrm{wt} / \mathrm{wt})$. The containers were placed in a vacuum oven at $25{ }^{\circ} \mathrm{C}$ and the pressure was reduced to near vacuum. The samples were kept at this pressure for 30 minutes, after which atmospheric pressure was restored slowly. The impregnated pieces of fruit were removed from the container and the excess solution removed from the surface. The samples were weighed again and the uptake of the solution was noted. Assuming that isotonic solutions do not have an effect on the structure of the cells, the amount of liquid that was incorporated is equal to the effective porosity, which can be interpreted as the fraction of the pores that are available for HDM. The effective porosity, $\epsilon$, is related to the weight gain as below:

$$
\epsilon=\frac{M_{f}-M_{i}}{\rho_{s} V_{0}}
$$

where $M_{f}$ is the final mass of the material, $M_{i}$ is the initial mass of the material, $\rho$ is the density of the solution and $V_{0}$ is the initial volume of the material. This only applies to fruit types that do not show a large DRP due to viscoelastic effects, as this would influence the structure of the cells. Previous studies have shown that firm fruits, such as apples and melons, suffer minor deformations, indicating that DRP can be neglected [4].

\section{Mechanical test}

Mechanical tests were carried out using a Texture Analyzer, equipped with a load cell of $50 \mathrm{~N}$ and a homemade razor blade. To measure the fracture toughness of the impregnated samples, a three point bending test was used, which has been shown to give good results for the determination of fracture toughness $[28,29]$. The samples were placed horizontally on the supporting carriers of the set-up. Prior to testing, the samples were notched with a razor blade to halfway through the sample, and the notch in the sample was placed facing down underneath the loading point. The ratio between the depth of this notch

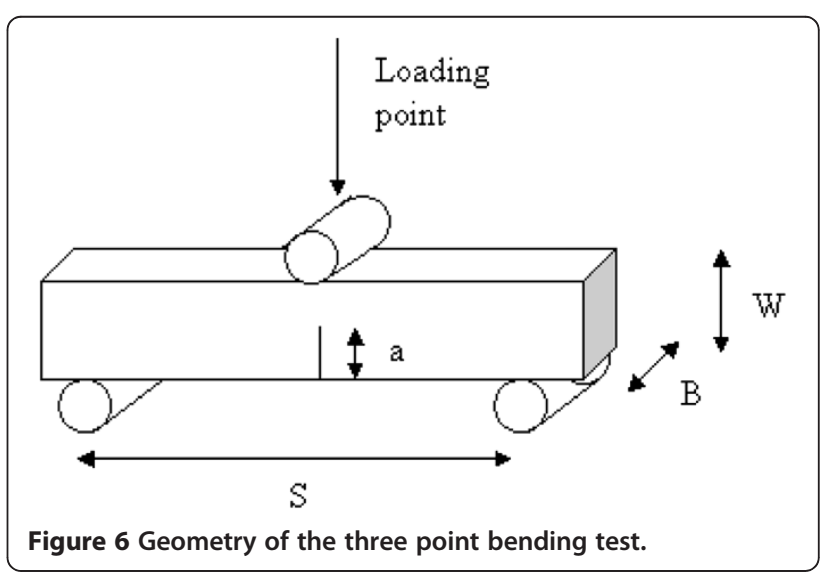


and the total width of the sample $(a / W)$ was between 0.45 and 0.55 . The razor blade was then lowered into the samples with a speed of $1 \mathrm{~mm} / \mathrm{s}$. The maximal force that corresponded to the onset of crack propagation was recorded for all samples. The measurements were performed three times, and the fracture toughness, $K_{I C}$ was calculated where $P_{c}$ is the maximal load before propagation starts, $S$ is the distance between the supports, according to:

$$
K_{I C}=\frac{P_{c} S}{B W^{3 / 2}} \cdot f\left(\frac{a}{W}\right)
$$

$B$ is the breadth of the specimen, $W$ is the width of the specimen and $a$ is the crack length. $F(a / W)$ is a correction factor, which is equal to 1.5 [30]. The geometry for the experimental set-up can be found in Figure 6. The subscript $I C$ refers to the mode I loading conditions.

\section{Competing interests}

The authors declare that they have no competing interests.

\section{Author details}

${ }^{1}$ Food Physics Group, Department of Agrotechnology and Food Sciences, Wageningen University, Bomenweg 26703HDWageningen, the Netherlands. ${ }^{2}$ FrieslandCampina Cheese \& Butter, Nieuwe Kanaal 7R6709PAWageningen, the Netherlands.

\section{Authors' contributions}

ES has made the major contribution to the design and drafted the article. MP performed the experimental work. Both authors read and approved the final manuscript

\section{Authors' information}

ES works as an assistant professor at Wageningen University. One of the interests of the Food Physics group is Molecular Gastronomy, which is part of the educational program. This field of science is focused on the link between science and real applications and/or innovations in restaurants and bars.

Received: 2 June 2011 Accepted: 2 November 2011

Published: 11 June 2012

\section{References}

1. Torreggiani $D$, Bertolo $G$ : Osmotic pre-treatments in fruit processing: chemical, physical and structural effects. J Food Eng 2001, 49:247-253.

2. Guillemin A, Degraeve P, Noel C, Saurel R: Influence of impregnation solution viscosity and osmolarity on solute uptake during vacuum impregnation of apple cubes (var. Granny Smith). J Food Eng 2008, 86:475-483.

3. Mujica-Paz H, Valdez-Fragoso A, Lopez-Malo A, Palou E, Welti-Chanes J: Impregnation and osmotic dehydration of some fruits: effect of the vacuum pressure and syrup concentration. J Food Eng 2003, 57:305-314.

4. Mujica-Paz H, Valdez-Fragoso A, Lopez-Malo A, Palou E, Welti-Chanes J: Impregnation properties of some fruits at vacuum pressure. J Food Eng 2003, 56:307-314.

5. Valdez-Fragoso A, Soto-Caballero MC, Blanda G, Welti-Chanes J, Mujica-Paz $\mathrm{H}$ : Firmness changes of impregnated whole peeled prickly pear. J Text Studies 2009, 40:571-583.

6. Lewicki PP, Porzecka-Pawlak R: Effect of osmotic dewatering on apple tissue structure. J Food Eng 2005, 66:43-50.

7. Fernandes FAN, Gallao MI, Rodrigues S: Effect of osmotic dehydration and ultrasound pre-treatment on cell structure: melon dehydration. LWT-Food Science and Technology 2008, 41:604-610.

8. Chiralt A, Martinez-Navarrete M, Martinez-Monzo J, Talens P, Moraga G, Ayala A, Fito P: Changes in mechanical properties throughout osmotic processes - Cryoprotectant effect. J Food Eng 2001, 49:129-135.

9. Sousa MB, Canet W, Alvarez MD, Fernandez C: Effect of processing on the texture and sensory attributes of raspberry (cv. Heritage) and blackberry (cv. Thornfree). JJ Food Eng 2007, 78:9-21.
10. Xie J, Zhao Y: Nutritional enrichment of fresh apple (Royal Gala) by vacuum impregnation. Int J Food Sci Nutrit 2003, 54:387-398.

11. Chiralt A, Fito P: Transport mechanisms in osmotic dehydration: the role of the structure. Food Sci Tech Int 2003, 9:179-186.

12. Fito $P, C$ Chiralt A: Food matrix engineering: The use of the water-structurefunctionality ensemble in dried food product development. Food Sci Tech Int 2003, 9:151-156.

13. Zhao YY, Xie J: Practical applications of vacuum impregnation in fruit and vegetable processing. Trends Food Sci Tech 2004, 15:434-451.

14. Salvatori D, Andres A, Chiralt A, Fito P: The response of some properties of fruits to vacuum impregnation. J Food Process Eng 1998, 21:59-73.

15. Vega C, Ubbink J: Molecular gastronomy: a food fad or science supporting innovative cuisine? Trends Food Sci Tech 2008, 19:372-382.

16. Cousins J, O'Gorman K, Stierand M: Molecular gastronomy: cuisine innovation or modern day alchemy? Int J Cont Hosp Manage 2010, 22:399-415.

17. McFeeters RF, Lovdal LA: Sugar composition of cucumber cell-walls during fruit development. J Food Sci 1987, 52:996-1001.

18. Fernandes FAN, Gallao MI, Rodrigues S: Effect of osmosis and ultrasound on pineapple cell tissue structure during dehydration. J Food Eng 2009, 90:186-190.

19. Vincent JFV: Application of fracture mechanics to the texture of food. Eng Fail Anal 2004, 11:695-704.

20. Vincent JFV, Saunders DEJ, Beyts P: The use of critical stress intensity factor to quantify "hardness" and "crunchiness" objectively. J Text Studies 2002, 33:149-159.

21. Harker FR, White A, Gunson FA, Hallett IC, De Silva HN: Instrumental measurement of apple texture: a comparison of the single-edge notched bend test and the penetrometer. Postharvest Biol Tech 2006, 39:185-192.

22. Khan AA, Vincent JFV: Anisotropy in the fracture properties of apple flesh as investigated by crack-opening tests. J Mat Sci 1993, 28:45-51.

23. Prasanna V, Prabha TN, Tharanathan RN: Fruit ripening phenomena - an overview. Crit Rev Food Sci Nutr 2007, 47:1-19.

24. Martinez VY, Nieto AB, Castro MA, Salvatori D, Alzamora SM: Viscoelastic characteristics of Granny Smith apple during glucose osmotic dehydration. J Food Eng 2007, 83:394-403.

25. Chassagne-Berces S, Poirier C, Devaux MF, Fonseca F, Lahaye M, Pigorini G, Girault C, Marin M, Guillon F: Changes in texture, cellular structure and cell wall composition in apple tissue as a result of freezing. Food Res Int 2009, 42:788-797.

26. Redgwell RJ, Curti D, Gehin-Delval C: Role of pectic polysaccharides in structural integrity of apple cell wall material. Eur Food Res Techn 2008, 227:1025-1033.

27. Kunzek H, Kabbert R, Gloyna D: Aspects of material science in food processing: changes in plant cell walls of fruits and vegetables. Eur Food Res Tech Z Lebensm Unters Forsch 1999, 208:233-250.

28. Pitts MJ, Davis DC, Cavalieri RP: Three-point bending: an alternative method to measure tensile properties in fruit and vegetables. Postharvest Bio Tech 2008, 48:63-69.

29. Alvarez MD, Saunders DEJ, Vincent JFV: Fracture properties of stored fresh and osmotically manipulated apple tissue. Eur Food Res Tech 2000, 211:284-290.

30. Wang CH: Introduction to fracture mechanics. Melbourne, Australia: DSTO Aeronautical and Maritime Research Laboratory; 1996.

doi:10.1186/2044-7248-1-10

Cite this article as: Scholten and Peters: The edible cocktail: the effect of sugar and alcohol impregnation on the crunchiness of fruit. Flavour 2012 $1: 10$. 